\title{
Roman KRAKOVSKY, Le Populisme en Europe centrale et orientale. Un avertissement pour le monde?
}

\section{Cédric Pellen}

\section{(2) OpenEdition}

1 Journals

\section{Édition électronique}

URL : http://journals.openedition.org/ress/6893

DOI : $10.4000 /$ ress.6893

ISBN : $1663-4446$

ISSN : $1663-4446$

Éditeur

Librairie Droz

Édition imprimée

Date de publication : 1 décembre 2020

Pagination : 254-257

ISSN : 0048-8046

Référence électronique

Cédric Pellen, "Roman KRAKOVSKY, Le Populisme en Europe centrale et orientale. Un avertissement pour le monde? », Revue européenne des sciences sociales [En ligne], 58-2 | 2020, mis en ligne le 01

décembre 2020, consulté le 03 décembre 2020. URL : http://journals.openedition.org/ress/6893 DOI : https://doi.org/10.4000/ress.6893

Ce document a été généré automatiquement le 3 décembre 2020.

(c) Librairie Droz 


\title{
Roman KRAKOVSKY, Le Populisme en Europe centrale et orientale. Un avertissement pour le monde?
}

\author{
Cédric Pellen
}

\section{RÉFÉRENCE}

Roman KRAKOVSKY, 2019, Le Populisme en Europe centrale et orientale. Un avertissement pour le monde?, Paris, Fayard, 350 p.

1 «Un incendie est en train de gagner la maison Europe ». Pour l'historien Roman Krakovsky, le constat est implacable: les valeurs démocratiques et libérales au fondement des sociétés européennes sont mises en péril par l'émergence d'un autoritarisme d'un type nouveau qu'il qualifie, suivant Fareed Zakaria, de «démocraties illibérales ». C'est dans l'espace centre-est européen, dont il est un spécialiste reconnu, qu'il situe le foyer de ce brasier " anti-Lumières ", qui consumerait déjà la Hongrie et la Pologne. Dans son essai, il se donne pour objectif de mettre au jour les fondements historiques de cette "dérive" politique qui menacerait à terme l'ensemble du continent.

2 L'analyse proposée se fonde sur deux postulats principaux. Le premier est celui de l'existence ancienne d'une tradition anti-libérale en Europe centrale et orientale. Puisant ses origines dans le XIX ${ }^{\mathrm{e}}$ siècle, celle-ci se serait perpétuée jusqu'à aujourd'hui en prenant, selon les époques, des formes variables, tour à tour agrariste, nationaliste, fasciste, communiste ou, plus récemment, conservatrice. Au-delà de leurs indéniables divergences idéologiques, ces différents mouvements se rejoindraient dans leur recours commun au populisme, que l'auteur définit, suivant Ernesto Laclau, comme une « logique politique tendant à reconstruire la notion de peuple à partir de groupes marginalisés ou qui se perçoivent ainsi ». Le second postulat est que les pays d'Europe centrale et orientale sont dotés de caractéristiques communes, qui transcendent leur 
apparente diversité culturelle, ethnique, religieuse ou sociale. Outre une histoire troublée - émaillée de dominations extérieures, de recompositions nationales et de conflits sanglants - ils partageraient une trajectoire de développement entravée, qui les aurait pareillement relégués à une position périphérique au sein du continent. Pour l'auteur, c'est justement cette "crise de modernisation » qui les constituerait en terreau particulièrement propice à l'émergence du populisme. Suivant ces deux postulats, la démonstration s'organise en six chapitres, selon une logique chronologique.

Identifiant les prémisses du populisme centre-est européen dans les dernières décennies de la Russie impériale, Krakovsky y consacre ses premiers développements. Il revient d'abord sur l'émergence du mouvement des Narodniki au XIX ${ }^{\mathrm{e}}$ siècle. Cette entreprise de contestation du tsarisme par la mobilisation d'une paysannerie idéalisée est en effet classiquement considérée comme l'une des premières expressions du populisme contemporain. De manière plus originale, l'auteur érige ensuite les bolchéviques en héritiers de ce populisme fondateur. Il soutient en effet que la manière dont ils ont mobilisé la figure de l'«ouvrier» pour légitimer le nouveau régime soviétique relève d'une logique analogue à celle mise en œuvre par les Narodniki à l'égard des paysans.

4 À l'issue de ces deux premiers chapitres, l'ouvrage délaisse totalement l'espace russe pour se concentrer sur la seule Europe centrale. Il s'intéresse d'abord aux conditions d'émergence de formations agrariennes puissantes dans les nouveaux États qui y voient le jour après 1918, sur les décombres des Empires centraux. Bien que ces agrarismes connaissent des évolutions et fortunes diverses, leur parenté avec le populisme des Narodniki apparaît relativement claire. Elle est nettement moins évidente en ce qui concerne les mouvements nationalistes qui fleurissent dans l'entre-deux-guerres, sur lesquels se porte ensuite l'analyse. Krakovsky estime pourtant que les logiques de mobilisation de ces radicalismes «identitaires" sont du même ordre, en ce qu'elles conduisent également à définir de manière dichotomique le peuple; cette fois selon des critères, non pas sociaux, mais ethniques et religieux. Poursuivant son travail d'identification des «logiques populistes", l'auteur se penche sur les régimes communistes qui s'établissent dans la région après la Seconde Guerre mondiale. Là encore, il souligne leur tendance à fonder leur légitimité sur l'« instrumentalisation » des divisions sociales (entre «travailleurs " et «bourgeois ») mais aussi, à l'occasion, ethniques. Enfin, il achève son périple historique en dressant un tableau inquiétant de l'état actuel de la démocratie en Europe centrale. Selon lui, les « insécurités » du postcommunisme y auraient réveillé les "démons du passé» et ouvert la voie à l'affirmation d'une forme nouvelle de populisme réactionnaire et étatiste. L'ouvrage s'achève par un épilogue dans lequel l'auteur formule une série de propositions pour combattre les «logiques populistes" sur lesquelles les "démocraties illibérales » construisent selon lui leurs succès actuels.

5 Cet ambitieux essai offre un panorama stimulant des évolutions politiques et sociales d'ampleur dont les pays d'Europe centrale et orientale ont été le théâtre depuis le début du $\mathrm{XX}^{\mathrm{e}}$ siècle. Il pointe avec justesse la dynamique heurtée des processus de constructions nationale, étatique et démocratique qui s'y sont développés, souvent dans un rapport de dépendance avec leurs puissants voisins occidentaux ou orientaux. Il mobilise par ailleurs des références historiques et littéraires originales qui en enrichissent la lecture et témoignent de l'érudition de son auteur. Du point de vue des 
sciences sociales, l'ouvrage appelle cependant plusieurs réserves majeures, dont trois apparaissent particulièrement problématiques.

6 Premièrement, l'essai souffre d'un usage peu rigoureux de l'approche comparative. L'ambition affichée par l'auteur d'englober dans son analyse l'ensemble des pays d'Europe centrale et orientale le conduit trop souvent à écraser de manière excessive la diversité de leurs dynamiques historiques, sociales et politiques, nourrissant même au fil de la lecture le sentiment désagréable de ne retenir que les éléments allant dans le sens de son postulat initial de convergence. Dans cette optique, le manque de constance dans la définition du cadre géographique de l'analyse ainsi que la tendance à juxtaposer les exemples nationaux plus qu'à véritablement les confronter, interrogent particulièrement.

7 Deuxièmement, l'ouvrage reste étonnamment aveugle aux conditions concrètes de circulation et de mobilisation des idées et répertoires politiques. Au fil des chapitres, les « logiques populistes » semblent transcender naturellement les époques, régimes et frontières, sans que ne soient jamais véritablement questionnés les différents acteurs qui participeraient en pratique à leur diffusion et mises en œuvre. Un détour par la socio-histoire des idées et la sociologie des mobilisations aurait permis à Krakovsky de se prémunir d'un tel écueil et de muscler une démonstration qui, en l'état, reste souvent trop surplombante pour pleinement convaincre.

8 Enfin, l'ouvrage choque par la naïveté de son rapport à la notion de populisme. D'une part, il ignore totalement la littérature, pourtant abondante, qui lui a été consacrée ces dernières décennies. D'autre part, loin de s'en tenir effectivement à la définition qu'en donne Laclau (dont l'importation au contexte centre-européen aurait par ailleurs méritée d'être davantage justifiée), il cède rapidement aux biais, bien documentés, induits par cette notion polysémique aux fréquents usages polémiques (voir Annie Collovald, 2004, Le populisme du FN : un dangereux contresens, Éditions du Croquant). En qualifiant de «logique populiste" l'ensemble des entreprises de construction dichotomique du peuple, indépendamment de leur contexte de développement, de leur nature (régimes établis et mouvements d'opposition sont ici placés sur le même plan) ou encore de leur idéologie parfois radicalement antagonique, Krakovsky la soumet à un «étirement conceptuel» extrême qui la vide progressivement de toute intérêt analytique (voir Giovanni Sartori, 1970, "Concept Misformation in Comparative Politics", The American Political Science Review, 64-4, p. 1035). D'autant plus que cet usage imprécis de la notion se double d'une approche pathologique, qui érige le populisme en symptôme d'anomalies dans le processus de modernisation. Or, un tel raisonnement n'a de sens que par rapport à une normalité dont la définition conduit inexorablement à naturaliser des préjugés développementalistes et à idéaliser un modèle occidental érigé en mètre-étalon du bon fonctionnement politique et économique. Il induit également une approche substantialiste du politique, postulant une différence radicale de nature entre les mouvements affublés du qualificatif de "populistes » et les autres, supposés "normaux». Ce faisant, le positionnement particulier des premiers dans les jeux politiques est naturalisé, sans véritablement fournir les moyens d'en saisir les fondements ou les évolutions. Il paraît pourtant difficile de comprendre les succès d'un parti comme Droit et Justice en Pologne, sans prendre en compte le travail politique par lequel ses dirigeants sont parvenus, non sans heurts ni revirements, à élaborer et à légitimer, en concurrence avec d'autres, une offre de représentation électoralement efficace (voir Frédéric Zalewski, 2016, «L'émergence d'une démocratie Antilibérale en 
Pologne ", Revue d'études comparatives Est-Ouest, 47-4, p. 57-86). En somme, si la place centrale accordée à la notion de populisme dans l'essai de Krakovsky lui a sans doute assuré une belle visibilité éditoriale, elle a en retour fragilisé la portée effective de son analyse et de ses réflexions. En faire l'économie lui aurait sans doute permis de mieux valoriser son travail de synthèse historique, ainsi que sa contribution indéniable à une meilleure prise en compte de l'influence du passé sur la structuration des jeux politiques contemporains en Europe centrale et orientale.

\section{AUTEURS}

\section{CÉDRIC PELLEN}

Université de Strasbourg, SAGE 